\title{
Photonics meet digital art
}

\section{Dan Curticapean, Kai Israel}

Dan Curticapean, Kai Israel, "Photonics meet digital art," Proc. SPIE 9188, Optics Education and Outreach III, 91880M (15 September 2014); doi: $10.1117 / 12.2061861$

SPIE Event: SPIE Optical Engineering + Applications, 2014, San Diego, California, SPIE. United States 


\title{
Photonics Meet Digital Art
}

\author{
Dan Curticapean $^{1 *}$, Kai Israel ${ }^{1}$ \\ ${ }^{1}$ Offenburg University \\ Badstr. 24 \\ 77652 Offenburg/Germany
}

\begin{abstract}
The paper focuses on the work of an interdisciplinary project between photonics and digital art. The result is a poster collection dedicated to the International Year of Light 2015. In addition, an internet platform was created that presents the project. It can be accessed at http://www.magic-of-light.org/iyl2015/index.htm.

From the idea to the final realization, milestones with tasks and steps will be presented in the paper. As an interdisciplinary project, students from technological degree programs were involved as well as art program students.
\end{abstract}

The 2015 Anniversaries: Alhazen (1015), De Caus (1615), Fresnel (1815), Maxwell (1865), Einstein (1905), Penzias Wilson, Kao (1965) and their milestone contributions in optics and photonics will be highlighted.

Keywords: Educations, Education in Optics and Photonics, Photonics and Art, International Year of Light 2015, IYL2015

\section{INTRODUCTION}

Both art and science are greatly shaped by their times. Even if the world of art evolved independently from science and technology, it did avail itself of them. Early Renaissance artists such as Da Vinci, Michelangelo and Raphael were universal geniuses of their time and combined the arts with science. They refined their painting techniques not only by developing higher-quality paint colors, but also by studying light, an elementary component of art. Albrecht Dürer, for instance, carried out extensive research to reproduce light as realistically as possible. His findings had a decisive impact on the further development of painting. Three centuries later, the impressionists, as for example Claude Monet, were intent on capturing the mood of light in their pictures. Throughout their lives, they worked on refining a variety of special techniques in order to achieve this aim.

With the invention of photography in the mid-nineteenth century [1], light design entered a new era. It was now possible to capture light directly, and thus form and frame it as well. Another milestone was the transition from analog to digital photography. If analog photography can still be interpreted as light painting, digital photography in comparison is light measurement - and as such, an element of photonics.

Art has been rapidly evolving since the dawn of digital technology. The works of established artists, e.g. David Hockney, have significantly contributed to this development [2], while thanks to the advance of photonics, the necessary technology has become accessible to the broader public.

\footnotetext{
* dan.curticapean@hs-offenburg.de
} 


\section{INTEGRATION OF PHOTONICS IN THE ARTS}

The integration of photonics in the arts is a major component of the International Year of Light (IYL). At Offenburg University's department of Media and Information, we utilized this context and encouraged our students to create their own art posters. The following milestones of the IYL 2015 served as starting points for the students, who went on to produce their individual interpretations of the events:

1015: Alhazen, Arabian mathematician, physicist and optician - inventor of the magnifying lens (loupe) -, completes his seven-volume treatise, "Treasure of Optics" [3]

1615: French-Huguenot engineer Salomon de Caus invents the prototype of a solar-driven engine [4],

1815: Augustin-Jean Fresnel introduces the theory of light as a wave [5] - [10]

1865: James Clerk Maxwell rigorously describes the electromagnetic theory of light [5] - [10]

1915: David Hilbert and Albert Einstein develop the theory of relativity, showing how light is at the center of the very structure of space and time [5] - [10]

1965: Arno Allan Penzias and Robert W. Wilson discover the cosmic microwave background, an electromagnetic echo of the very creation of the universe [11] - [13]

Selected examples of this interdisciplinary project are shown in figure 1 below. Students were also allowed to bring in their own ideas in the creation of the art posters. As a result, more recent events were incorporated as well. Most prominently, the 2014 FIFA World Cup was picked up as a topic, which resulted in the independent poster series, "No football - just photonics." The core idea of the series is to transfer optical components and devices: an optical comb generator, Raman scattering, a photo coupler, an optical ring resonator, an optical fiber, an optical amplifier, a Mach-Zehnder coupler, as well as erbium-doped fiber amplifiers, all working their magic on a soccer field (see figure 2) [14].

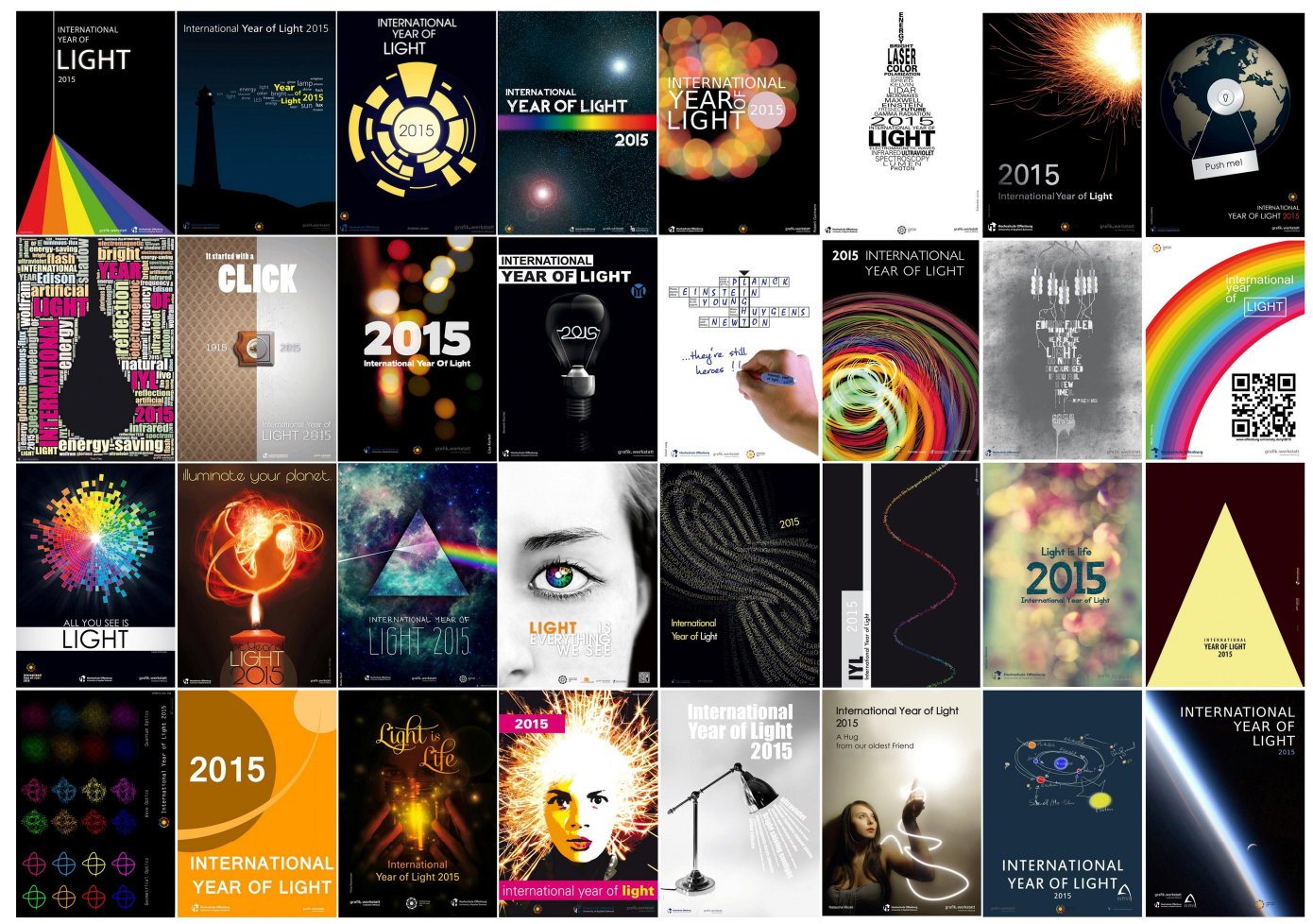

Fig. 1: Art-Poster collection (C) www.Offenburg-University.de/iyl2015 
The feedback on the first presentations of the poster series to the optical community (SPIE - International Society for Optics and Photonics, OSA - Optical Society of America, EPS - European Physical Society) [15] was exceedingly positive. After receiving a large number of requests, we decided to make the students' designs accessible to the worldwide community.
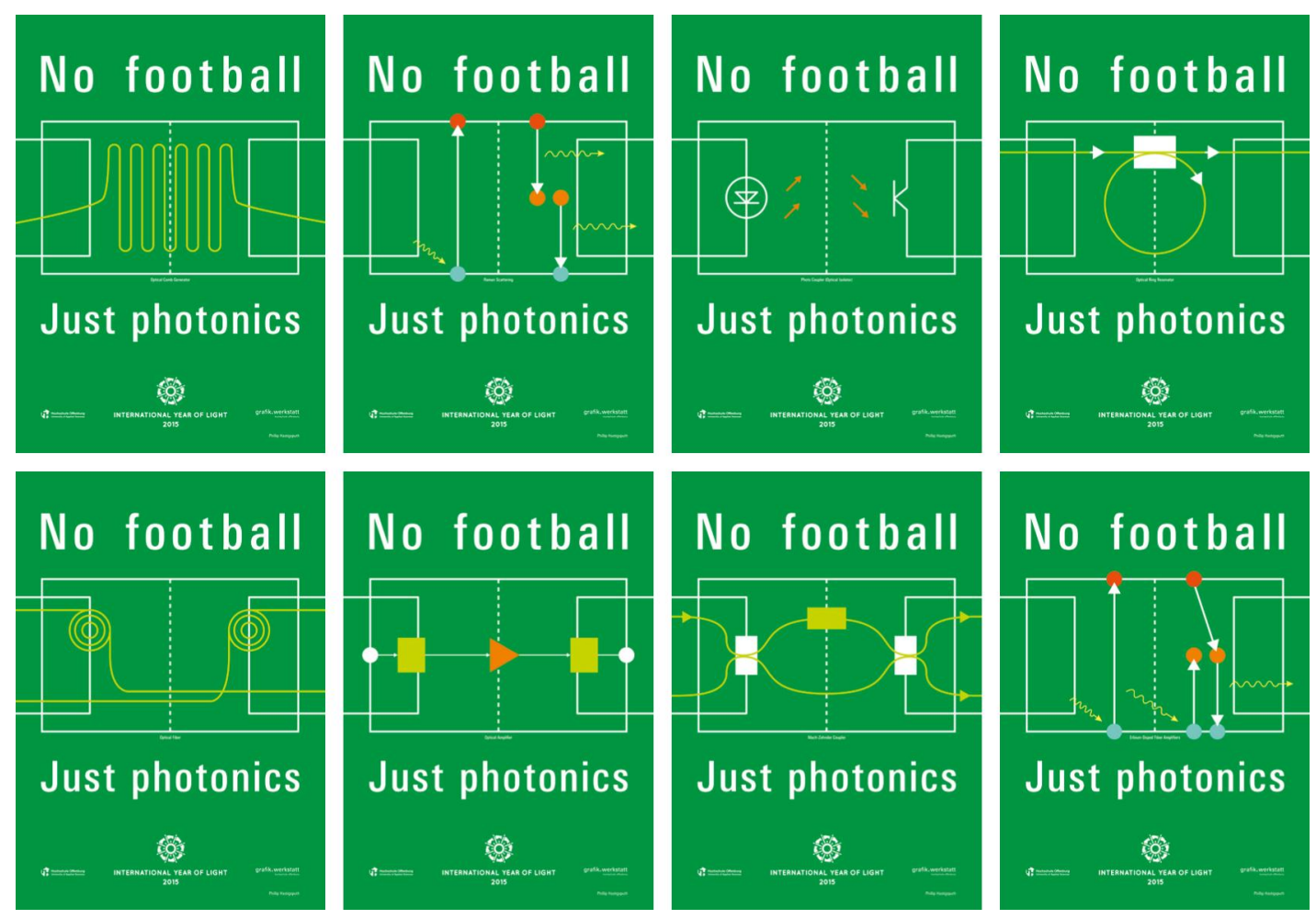

Fig. 2: Artwork Poster: No football - Just Photonics; ${ }^{\complement}$ www.Offenburg-University.de/iyl2015

\section{BUILDING A WORLDWIDE COMMUNITY PLATFORM}

To achieve the most far-reaching effect, the website on the International Year of Light 2015 went online in April 2013. The website has a clear and simple design and reaches beyond the experts to get the broad public interested and involved in the IYL. Everybody can participate directly. Both the entirely positive feedback and the access numbers are proof that this aim has been achieved: With more than 4,100 unique visitors from around the world, the website has become an essential element of the worldwide community. Globally active companies apparently confirm the website's success - try googling "International Year of Light 2015" in this regard. Beyond the availability of information, much of this success is certainly due to the possibility to become actively involved in the project. Applying a variety of web technologies, what started as a static website has been turned into a lively community platform.

Web 2.0 has been established for many years now and enriches our daily life in almost every aspect. Visitors to a website are now able to not only consume its contents, but contribute to them as well. One such "user-generated content" on the IYL website is a world map where every visitor can register their locations. The address data are automatically converted into geo-coordinates, allowing for exact positioning. As an optical highlight, the IYL logo appears on the world map instead of the usual marker. Thus every user can signal their support for the IYL 
to the global community. The database installed to register these signals shows that since July 2013, more than 305 visitors to the website have placed their individual markers this way. That this success started well before the United Nations in New York officially proclaimed (on 20 December 2013) [16] that 2015 would be the International Year of Light and Optical Technologies, also proves the awareness-raising function of the website. It is thus the merit of the entire community that the $\mathrm{UN}$, based on the map entries, could see the worldwide interest in the subject and went on to establish 2015 as the International Year of Light.

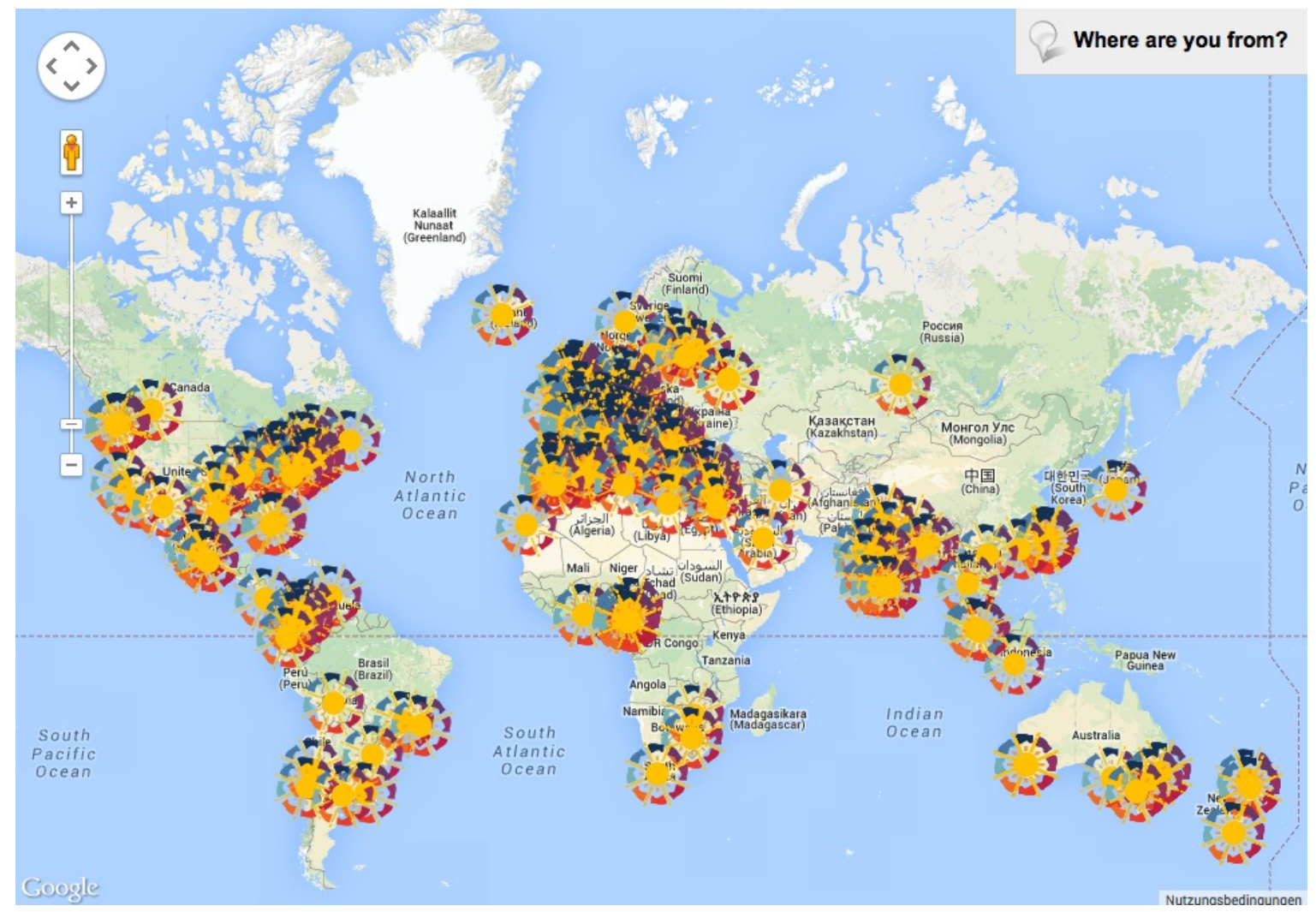

Fig. 3: Worldwide community entries; (www.magic-of-light.org/iyl2015/map.php )

To present the IYL adequately around the world, Offenburg University students designed creative posters in the context of a lecture on digital design. These high-resolution, printable posters were also stored on the website for downloading. After a registration process, visitors can download a great variety of designs related to the IYL. This allows for exhibitions and events on the subject of the IYL to be organized and marketed without incurring considerable costs. So far, the posters have been presented to larger audiences at the following events:

- International Congress Center at Laser Munich (May 2013): European Conference on Lasers; ElectroOptics, International Quantum Electronics Conference OSA, EPS, Optical Metrology 2013 SPIE

- Education \& Training in Optics \& Photonics in Porto (July 2013): OSA, SPIE, EPS Conference

- Optics \& Photonics in San Diego (August 2013): SPIE Conference

- Frontiers in Optics in Orlando (October 2013): OSA Conference

- Allied Arts of Whatcom County in Bellingham, WA/USA (January 2014) [17]- [18]

- Opening Ceremony, UNESCO Headquarters in Paris (January 2015, in planning) 


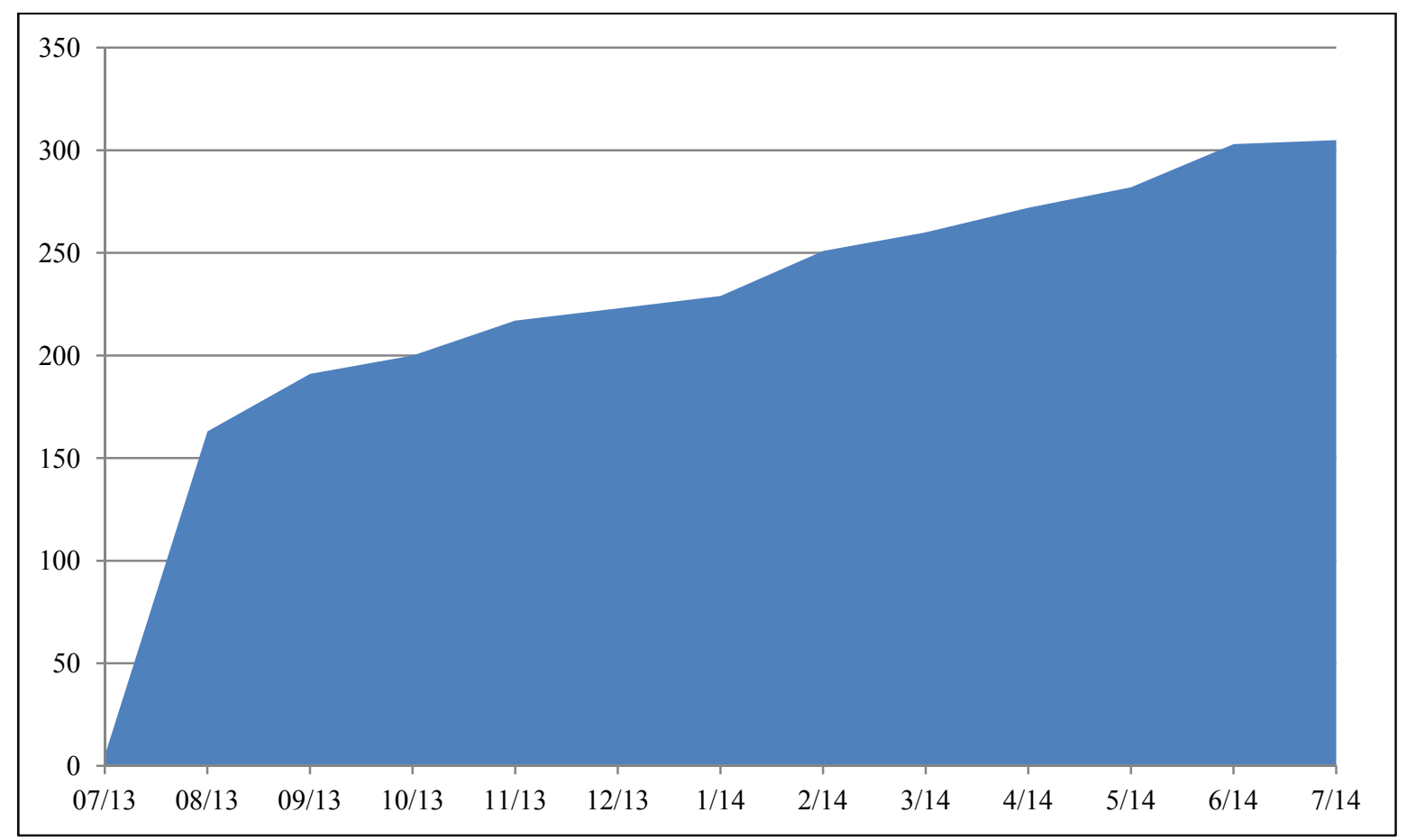

Fig. 4: Community marker registrations

The download numbers also demonstrate the popularity of these posters among professionals and private individuals alike: As of June 2014, a total of 1,502 files have been downloaded from the website by 200 registered users, including school students, university student chapters, scientists, professors, but also private individuals interested in the subject. The posters have been used for various educational purposes and PR work, such as locally announcing the IYL. Some users have also contacted us offering their help, e.g. to translate the posters into their native language or to print them as postcards or t-shirts.

\section{CONCLUSIONS AND PERSPECTIVES}

We have been very happy about this opportunity to present our students' works to the world at the same time as supporting the special cause of making the IYL happen and publicizing it. The project continues to be exciting; currently, as of 22 July 2014, our website (http://www.magic-of-light.org/iyl2015) comes in second place when googling the search term "International Year of Light"! With it we hope to awaken young people's interest and enthusiasm for physics, and for optics in particular, as a science of the future. 


\section{BE PART OF THE COMMUNITY!}
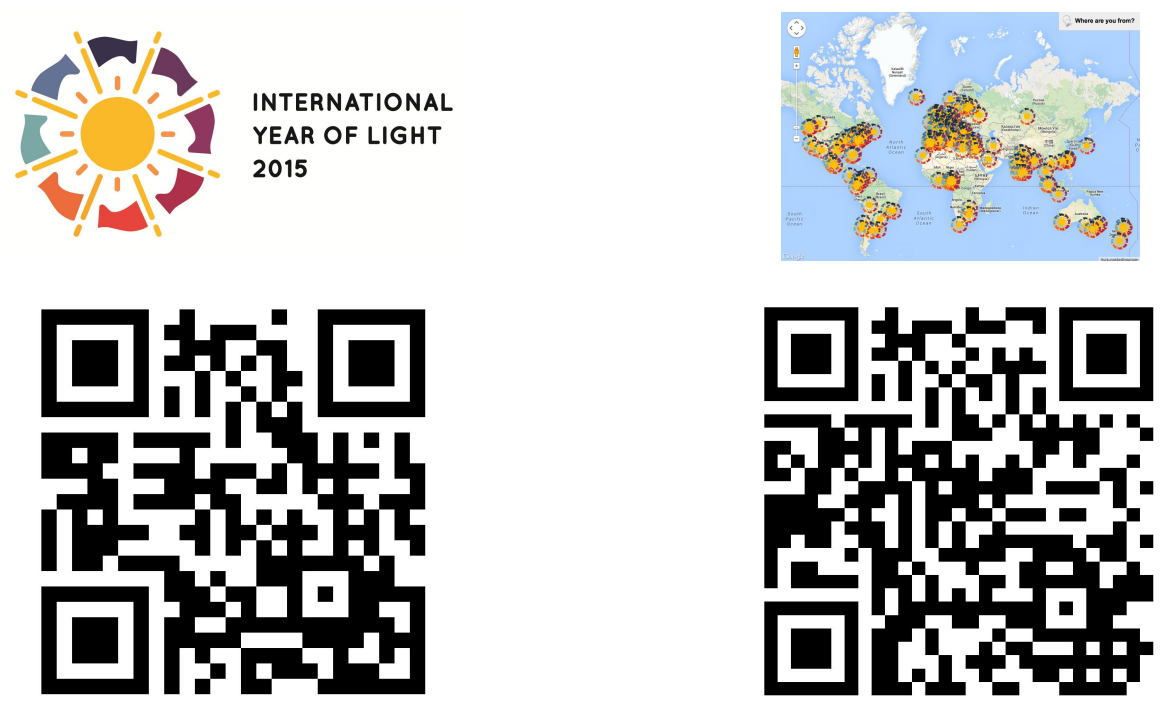

\section{REFERENCES:}

[1] Ang, T., [Photographie], Dorling Kindersley Limited, London (2005)

[2] Barringer, T., Devaney E., Drabble, M., Livingstone, M., Gayford, M., Salomon, X. F., [David Hockney: A Bigger Picture], Royal Academy of Arts, London, (2012)

[3] ***, "1000 Years of Arabic Optics", 10 July 2014, http://www.light2015.org/Home/ScienceStories/1000-Years-of-Arabic-Optics.html (10 July 2014)

[4] Morgan, L., [Nature as Model: Salomon De Caus and Early Seventeenth-century Landscape Design], University of Pennsylvania Press (2006).

[5] Tipler, P. A. and Llewellyn. R. A., [Moderne Physik], Oldenbourg Verlag, München, (2010)

[6] Tipler, P. A. and Mosca, G., [Physisk für Wissenschaftler und Ingenierue], Spektrum Akademischer Verlag, Heidelberg, (2009)

[7] Knight, R. D. [Physics for Scientists and Engineers a strategic approach second edition], Pearson Addison-Wesley, San-Francisco, (2008)

[8] Orear, J., [Physik], Carl Hanser Verlag, München \& Wien, (1982)

[9] Radi, H. A., [Principles of Physics for Scientists and Engineers], Springer-Verlag, Berlin \& Heidelberg, (2013)

[10] Alonso, M. and Finn, E. J., [Physik], Addison-Wesley, Bonn \& München, (1988)

[11] Jeffrey, B., Donahue, M., Schneider, N., Voit, M., [Astronomie - Die kosmische Perspektive], 5. Auflage, Pearson Education, München, (2010).

[12] Comins, N. F., [Astronomie], Springer Science+Business Media, Heidelberg, (2011)

[13] Kilian, U., Aschemeier, R., [Das große Buch vom Licht], Wissenschaftliche Buchgesellschaft, Darmstadt, (2012) 
[14] Curticapean, D., [Photonics is a player at the FIFA World Cup], http://spie.org/x108899.xml

[15] Huchet,B., "IYL 2015 - Draw the magic of light", 27. Feburary 2014, http://www.epsnews.eu/2014/02/iyl2015-magic-of-light/ (10. July 2014)

[16] Nelson, A., "United Nations proclaims an International Year of Light in 2015", 10 July 2014, http://www.light2015.org/Home/About/Latest-News/Dec2013/23Dec2013.html (10 July 2014)

[17] Nelson, A., "SPIE to Celebrate Light in Art and Technology at Gallery Show", 28 December 2013, http://www.prweb.com/releases/2013/12/prweb11449343.htm (7 January 2014)

[18] ***, "The Art of Light and Technology", 30 January 2014,

http://calendar.bellinghamherald.com/bellingham_wa/events/show/368966961-the-art-of-light-andtechnology (3 Feburary 2014) 